$1-1-1888$

\title{
The history, properties, source of the ingredients, mode of application, and uses of commercial fertilizers
}

\author{
A. R. Whitehill
}

Follow this and additional works at: https://researchrepository.wvu.edu/ wv_agricultural_and_forestry_experiment_station_bulletins

\section{Digital Commons Citation}

Whitehill, A. R., "The history, properties, source of the ingredients, mode of application, and uses of commercial fertilizers" (1888). West Virginia Agricultural and Forestry Experiment Station Bulletins. 2.

https://researchrepository.wvu.edu/wv_agricultural_and_forestry_experiment_station_bulletins/2 @ WVU. It has been accepted for inclusion in West Virginia Agricultural and Forestry Experiment Station Bulletins by an authorized administrator of The Research Repository @WVU. For more information, please contact ian.harmon@mail.wvu.edu. 
West Virginia University Libraries 



\title{
BULLETIN NO. 2.
}

\author{
OF THE
}

WEST VIRGINIA

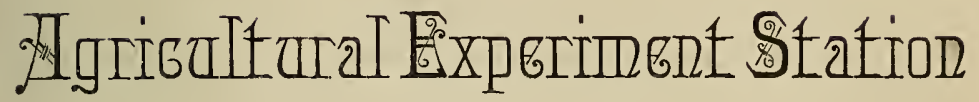

$\mathrm{AT}$

MORGANTOWN, W. VA.,

OOTOBER 1888.

The History, Properties, Source of the Ingredients, Mode of Application, and Uses of Commercial Fertilizers.

BY A. R. WHITEHILL.

JOHN A. MYERS, Director. 
Digitized by the Internet Archive in 2010 with funding from Lyrasis Members and Sloan Foundation 
Board of Regents of West Va. University.

Dist. Name of Regent.

P. O. Address.

1. J. B. SOMMERVILLE, - - - Wheeling.

2. CLARENCE L. SMITH, - - - - Fairmont.

3. PEREGRIN HAYS, - - - - - Glenville.

4. D. D. JOHNSON, - - - - Longreach.

5. JOHN G. SCHILLING, - - - - Spencer.

6. EDWARD A. BENNETT, - - Huntington.

7. WIRT A. FRENCH, - - - - Princeton.

8. M. J. KESTER, - - - - - - Union.

9. D. C. GALLAHER, - - - - Charleston.

10. THOMAS J. FARNSWORTH, - Buckhannon.

11. JOSEPH MORELAND, - - - Morgantown.

12. JOHN A. ROBINSON, - - - Patterson's Creek.

13. DR. W. W. BROWN, - - - - Charlestown.

Members of the Executive Board.

JOHN A. ROBINSON, CLARENCE L. SMITH,
J. B. SOMMERVILLE, 'THOMAS J. FARNSWORTH, JOSEPH MORELAND.

Members of the Building Committee;

JOHN. A. ROBINSON, D. D. JOHNSON,
CLARENCE L. SMITH, JOHN G. SCHILLING, W. W. BROWN.

Treasurer,

JOHN I. HARVEY,
Secretary,

W. P. WILLEY, 
Officers and Staff of the West Virginia Experiment Station,

Director and Chemist,

Dairyman,

Assistant Chemist,

66

Meteorologist and Assistant Chemist, Microscopist, Ornithologist, Botanist, Veterinarian, Agricultnrist, Horticulturist, Stenographer and Book-keeper,
John A. Myers.

A. C. Magruder.
A. R. WhitehilL.

J. W. Hartigan. William D. Doan. 


\section{COMMERCIAL FERTILIZERS.}

BY A. R. WHITEHILL.

Agriculture in recent years has developed into a science. Not that its underlying principles are yet thoroughly understood, but they have been carefully classified and studied, and many of them are capable of experimental demonstration. In its various departments agriculture is, in fact, a combination of all the other sciences. In the formation of soils and classification of plants, in the study of the various forms of animal life and in tracing the effects of different climatic conditions upon various crops, the sciences of geology, botany, anatomy and meteorology give valuable aid, while by the laws of physics and chemistry the use of machines is explained and the various forces of nature are interpreted.

While a knowledge of all these sciences is necessary to a correct understanding of the principles of agriculture, yet chemical science has been especially active in the interests of the farmer. There is hardly an operation performed on the farm which has not a direct bearing upon chemical science, and the study and explanation of these various operations may well claim the attention of the agriculturist. In the development and growth of the commercial fertilizer trade during the last half century, the importance of chemistry in agriculture has been especially marked, and plant food is now prepared with the same scientific care as that intended for animals or man.

With the introduction of Peruvian gnano into Europe the trade in commercial fertilizers may be said to have begun. It is true before this time crushed bone had played an important part in European agriculture, but its fertilizing properties were ascribed wholly to the animal matter which it contained. It 
was not until about fifty years ago that the keynote to scientific farming was struck by the Duke of Richmond when he affirmed that fertilizers owed their value largely to the phosphoric acid which they contained, and about the same time Boussingault in France and Liebig in Germany arrived at the same conclusion.

This statement, vouched for by such eminent authority, that the mineral food of the plant, as furnished partly by the earthy matter of the bone, was the important factor in agriculture was soon subscribed to by the other scientific writers of the countries named, and soon the expediency of manufacturing fertilizers began to be discussed. Not that the time was yet ripe for their immediate use, but so strong was the belief in the possibility of their preparation that Liebig in his famous work on chemistry made use of the following significant sentence: "A time will come when plants growing upon a field will be supplied with their appropriate food prepared in chemical manufactories, when a plant will receive only such substances as actually serve it for food, just as at present a few grams of quinine are given to a patient afflicted with fever, instead of the ounce of wood which he was formerly compelled to swallow in addition."

\section{THE ORIGIN OF FERTIIZERS.}

Even at this time guano ra as being imported in small quan. tities into Europe, and so marked were the results from its application that the subject of artificial plant food becime at once prominent in scientific agriculture. Without understanding its action, farmers soon saw that by the use of the substance the fertility of new fields could be increased and barren tracts could be reclaimed. They saw that larger and better crops could be obtained by its application than by the use of any other fertilizer then known, and quickly drawing out of the ruts into which they had fallen, a more lucrative system of farming soon prevailed.

When they saw, too, in the increased production of their farms what remarkable results would follow the use of a product, which, though expensive, required so little labor to handle and apply, they were easily induced to try other artifi- 
cial substances which soon began to be introduced. From this beginning sprang the immense fertilizer trade of the present, a trade which has erected the chemical manufactories foretold by Liebig in nearly every part of the globe, and which will increase in importance as lands become less fertile and the demand for food increases.

\section{THE TRADE IN WEST VIRGINIA.}

In West Virginia the trade is yet in its infancy as compared with it in some of the Eastern and Southern States, but it is becoming more extensive every year. New brands are being introduced, and the quality of the older brands, in many cases, is being improved. Every variety of soil and climate being found, every variety of fruit and grain and root crops can be successfully cultivated, and both immigration and a more advanced system of farming are adding to the farmer's wealth. In the older States farmers have long since learned, and many of them by sad experience, too, that valuable constituents cannot be taken from the soil and sold off the land, whether in the shape of grain, fruit, wool, dairy products or otherwise, without selling also valuable ingredients of the soil, and unless these ingredients be returned, crops will refuse to grow and fertility will cease. The worn out tobacco lands of many of the Southern States and the decrease in the production of wheat and other grains in many of the Northern States is a familiar illustration of the above fact, and it is the rule everywhere that unless the loss of mineral ingredients be made good, no land can be continually cropped without being the worse for the cropping.

In consequence of the growing importance of the fertilizer trade in West Virginia, it is proposed 11 this paper to inquire into the source and properties of the various substances that are being placed on the market, to give some practical information concerning their value and use, and thus aid the farmer in selecting that material which his soil and crop may require.

THE FOOD OF THE PLANT.

It is now generally concerled by agriculturists that plant cells are never formed except in a fluid containing oxygen, hydrogen, nitrogen and carbon. These four elements are 
generally termed the organic constituents of the plant, and so essential are they to its growth that they form the greater part of its structure. Existing in the atmosphere in the form of carbonic acid, water, ammonia and nitric acid, they find their way into the soil, and the simplest cell has the power to assimilate them. The hydrogen and oxygen form the water, which is the most abundant constituent of all. Three-fourths of the weight of many plants is merely water, while in beets, carrots and the succulent vegetables the proportion is still greater. Even a poplar tree is more than one-half water, while a ton of turnips contains only two hundred pounds of solid matter and eighteen hundred pounds of water. This water is taken into the plant through the roots, and in addition to forming such a large proportion of the weight, it serves as a carrier and solvent for the other ingredients.

The carbonic acid which exists in the air in the proportion of about oue part by volume to every twenty-five hundred of air furnishes some additional oxygen and the whole of the carbon to the plant, and in this case the leaf is the medium of introduction. The ammonia and nitric acid, which are found in the free state in the atmosphere are washed down by the rain into the soil, and the supply being increased in the soil, they are taken into the plant by the root and an additional supply of oxygen and hydrogen and all of the nitrogen is furnished. These four substances, then, water, carbonic acid, nitric acid and ammonia exist both in the atmosphere and soil, and the two former being present in such quantity no additional mention of their properties is needed.

THE IMPORTANT INGREDIENTS.

When the plant is burned the oxygen, hydrogen, nitrogen and carbon are thrown back into the atmosphere in the combinations above mentioned, and a white ash remains behind. This ash contains the mineral elements of the plant, and although these elements form only a very small part of the whole, they are none the less important. This ash contains the silica, lime, magnesia, iron, potash. soda, phosphorus, sulphur and chlorine which are essential to plant life, and which, being in solution in the water, are taken in through the roots and become a part 
of the general structure. Except the nitrogen, phosphoric acid and potash, of all the above constituents the soil generally contains sufficient, and if there be a deficiency in any one the same can usually be easily and cheaply supplied.

Therefore, says George E. Waring in his work on Agriculture, it is chiefly desirable for the farmer to give his attention to the sources from which the plant may derive its three important ingredients; for without them none of our cultivated plants will attain their full development, and when a soil ceases to produce good crops, it is almost always in consequence of a deficiency of one or more of them. The farmer raises no crop which does not contain them, he sells no animal or vegetable product which does not take them from his farm, and he has no soil so rich that they or some of them need not be returned to keep up its fertility Whatever course of cultivation he pursues he should never lose sight of these elements, and he should pay no greater heed to the dollars and cents he receives and pays out than to the nitrogen, phosphoric acid and potash, which constitute his real available capital, and whose increase and decrease mark the rise and fall of his true wealth. Such being the case, it is the business of the farmer to learn something of the nature of the soil which he cultivates, and if these necessary ingredients be not present in their proper state and proportion, then measures should be taken to supply what is needed.

\section{DIFFERFNT BRANDS OF FERTILIZERS.}

Of the numerous brands of commercial fertilizers in the market, some contain one of these important ingredients, some two, and others all of them. Dissolved bone biack and dissolved South Carolina rock contain phosphoric acid, but no nitrogen nor potash. The potash salts contain only potash, while nitrate of sodium, sulphate of ammonium and dried blood contain only nitrogen. The superphosphates, which comprise the bulk of the.fertilizers in the market, contain phosphoric acid as well as potash and nitrogen, and these are made by mixing different substances which contain the ingredients mentioned. The nitrogen may he obtained from the sulphate of ammonium or nitrate of sodium or from some animal or vegetable product 
which may furnish this element in an available form. Dried fish, blood, meat, fine ground bone, cotton seed, tankage, horn shavings and similar products are used for the purpose, and the commercial value of the nitrogen will vary with the material from which it is obtained, that from dried fish and blood being worth more than twice as much as that obtained from horn shavings, hair or fish-scrap.

The phosphoric acid is mostly obtained from bones and rock phosphates and the potash from the muriate, sulphate and kainite. The commercial value of the phosphoric acid and potash varies, too, with the products from which they are obtained, but the variation is not so marked as in the case of nitrogen. The superphosphate as well as the acid phosphate contains a considerable amount of sulphate of lime or gypsum, it being one of the products when the sulphuric acid is applied to the bones or rock phosphate. There may also be found some magnesia and perhaps some iron, silica, soda, chlorine and alumina, but they are not estimated in determining the value of the mixture. Sometimes also a filler is added, not for the purpose of defrauding any one, but for the purpose of increasing the bulk of the fertilizer, and, therefore, make it less concentrated and so cost less by the ton. It is now proposed to examine the source and properties of the various ingredients in turn, and thus learn something of the true nature and composition of the fertilizer.

THE SOURCES OF NITROGEN.

Nitrogen, as has been stated, is one of the organic constituents of the soil and plant, and the only one which it is necessary to add in the fertilizer. It exists in abundant quantities in the atmosphere, being about four-fifths of the whole. It surrounds the plant on every side, hut, as free nitrogen, the plant is pow erless to assimilate it. Tantalus in the midist of water conld not even procure a drop to drink, and the plant, enveloped in an atmosphere of nitrogen, cannot take the trifle without which it cannot exist. It is a case of want, and often death, in the midst of plenty, but nature's laws are mysterious m their workings, yet always perfect when rightly interpreted.

The nitrogen is not only essential to every plant, hut to every part of the plant. Root, stem, branch and leaf must 
each have its proper share, and this must be derived through the root from its combinations in the soil. The ammonia and nitric acid in the atmosphere are washed down by the rain, and these with the humus in the soil are the natural sources of the nitrogen. The nitric acid, which is claimed to be the true source of this important element combines with mineral matters in the soil to form nitrates, but by far the larger quantity of nitrates are formed by the oxidation of ammonium compounds and the animal and vegetable matter.

The nitrification of the soil, or the manner in which the element gets into the plant, has long been an extremely difficult problem in scientific agriculture, but Pasteur and others have finally agreed that it is due to fermentation, something similar to that which is formed in yeast, and which requires some nitrogenous form to give the organisms life and vigor. Very little nitrogen is found in the average soil, and very little is taken up by the plant. It has been estimated that in 4,000,000 lbs. of arable soil, which is abont the weight of an acre to the depth of one foot, 2 So pounds of nitrogen in an assimilable form is sufficient to produce a maximum crop of wheat, while far less would be sufficient for rye and still less for oats. Not much then of this important element is needed for the plant, but the soil may easily be exhansted of the littie it contains, and if this be not restored the plant will not grow.

Nitrogen is known to the fertilizer trade in three forms. It can be purchased as nitric acid in nitrate of sodium as ammonı in sulphate of ammonium, and as organic nitrogen, found in various animal and vegetable substances.

NITRATE OF SODIUM.

This is sometimes called Chili saltpetre, hecause it is found as an incrustation on the soil in Chili and elsewhere in South America. As met with in commerce the salt is not quite pure, but generally has about five per cent. of alulterations. When pure it contains 16.4 per cent. of nitrogen, and hence about $6 \frac{1}{2}$ pounds of the salt is necessary to furnish one pound of nitrogen. When applied to the soil it serves a double purpose in that it furnishes the nitrogen which is essential to the plant growth, and it stimulates the plant to collect the other materials 
which are also necessary to its existence. Frequently twice and three times as much nitrogen is taken off in the crop as could be derived from the nitrate of sodium supplied, and this fact can only be explained on the ground that the plant is stimulated to unlock the comparatively inert soil nitrogen, and thus gain an additional supply of food. This same may be said of guano and sulphate of ammonium, and so efficacious are they in rendering the soil nitrogen available, that it has been suggested to supply in the fertilizer about half as much nitrogen as would be removed in the full crop.

\section{SULPHATE OF AMMONIUM.}

This is the only cheap salt of ammonium, and the only one within the reach of the agriculturist. It is prepared on a large scale in the manufacture of illuminating gas, and is also found native. When pure it contains 2 I.2 per cent nitrogen, but it is seldom found pure, and 5 pounds of the crude sulphate will generally furnish one pound of nitrogen. It has been estimated that the distillation of 100 tons of coal will furnish one ton of the sulphate or about 400 pounds of nitrogen, and nitrogen in ammonium salts has a somewhat greater commercial value than nitrogen in nitrates.

ORGANIC NITROGEN.

Substances containing nitrogen as organic matter may be animal in their origin, as dried blood, ground fish, flesh meal, bone, horn shavings, hair, wool waste, leather scrap, tankage and such like products, or vegetable, as rape cake, oil cake, soot, cotton seed meal and castor pomace. The value of the nitrogen in these various products varies at present from i7 cents per poind in fish, blood, cotton seed and castor pomace, to $S$ cents in hair, horn shavings and coarse fish scrap. Most animal and vegetable substances being rich in nitrogen, most of these waste products can be utilized in the manufacture of fertilizers, and the value of such products is generally determined by their mechanical division, and by the readiness with which they give up the important element.

It is not possible for the farmer to determine what preduct is utilized in the particular fertilizer which he purchases, but he 
may come near the truth by noting the locality in which the superphosphate is prepared. If it be prepared in the East fishscrap or some chemical salt is probably used in the manufacture; if in the South cotton-seed meal is the product, and if in the North or West dried blood, tankage, bones and like products are the sources of the nitrogen. It is one of the triumphs of modern chemistry that products which a few years ago were considered worthless, and could not be disposed of without great expense, are now largely used in the manufacture of fertilizers, and serve an important purpose in furnishing the foodsupply of the nation.

\section{GUANO.}

In addition to the nitrate of sodium, sulphate of ammonium and the organic products mentioned above, Peruvian guano may be classed among those substances which are capable of supplying ammonia or nitrates to the soil. Unlike most of the substances already mentioned, however, guano contains in addition to the nitrogen a considerable amount of phosphoric acid and potash, but the nitrogen being present in large quantities and being the most valuable ingredient, the substance may be fitly classed with those which give nitrogen to the plant. Peruvian guano is the best known of the artificial manures, and at the same time it is one of the richest and longest in use. When it was first imported into Europe, about half a century ago, it was very rich in organic matter containing nitrogen and also in ammonium salts. An average analysis made only twenty-five years ago by Dr. Voelcker showed nearly ig per cent. of ammonia, but the guano of to-day will scarcely average one-half of that amount. The falling off in the quality of the material is probably due to the rapid exhaustion of the beds, and at present there is not a great deal of the genuine article in the market. The guanos whose analyses are found so frequently in the agricultural reports are mostly guanos only in name, they being artificial manures prepared like the superphosphates. During the last season in Georgia no less than 32 brands of so-called guano were exposed for sale, and no one of these contained as high as 3 per cent. of nitrogen.

The genuine gilano consists of the accumulated refuse of sea 
fowls, and is found on certain islands off the cost of Peru. This refuse has lain undisturbed for many centuries, and besides the ammonium salts, it contains a great deal of uric, oxalic and phosphoric acids. For the accumulation and preservation of the guano, certain natural conditions seemed to have been necessary, among the more important of which were an extreme abundance of fish food, an almost entire absence of rain and a limited area to serve as a resting and brooding spot for the birds. So important was the second of these conditions that in regions. where the rain fell the guanos are called phosphatic guanos, the soluble and nitrogenous matters having been lagely washed out by the water, the less soluble and phosphatic matter alone remaining. This is the condition of the Baker, Jarvis and Howland guanos, and these products are scarcely worth one-half as much as those which come from rainless regions. The modes of applying the nitrogenous manures, and the crops most benefited by their application, will be considered in a subsequent section of this paper.

\section{SOURCES OF PHOSPHORIC ACID.}

It is generally conceded that when any soil has been exhausted by improper farming in nine cases out of ten it is the phosphoric acid that is gone. Not that the total amount of this essential ingredient has been removed from the soil, for the analysis of a fertile soil would show within a foot of the surface an amount of phosphoric acid sufficient for one hundred crops, but the improper farming has gathered up every atom that is available, and left only that which is in the insoluble state. The actual loss of nitrogen from the soil is at no time great. This being an element which exists in every part of the plant-root, stem, grain and leaf, much of it finally gets back into the atmosphere and thence into the soil by natural means, and becomes again available to plant life. Potash, too, existing in larger quanties in the soil, and being produced by the decomposition of felspar and other rocks is a somewhat permanent constituent of the soil, and its absence is only felt after many seasons of continuous cropping.

With phosphoric acid, however, the case is very different. In the early growth of the plant, being found in the young 
organs, especially in the leaves, in the later stages of growth it has accumulated largely in the seeds and fruit, and these being sold off the land, the soil is robbed of its most valuable ingredient. Being a fixed ingredient, it is not returned by the wind or rain, and its loss can only be made good by the use of the fertilizer. Nor is there much phosphoric acid in the soil as compared with the other ingredients. Even in the most fertile soils seldom is one per cent. found, while the average quantity is less than one-half of that amount. "A clay !oam soil," says Lloyd, "six inches deep and covering an acre of ground is estimated to weigh one thousand tons. If this soil contains two-tenths of one per cent. of phosphoric acid there will be about 5,000 pounds to the acre. But should a soil of peaty nature weigh only 500 tons to the acre, then there will be only one-half as much phosphoric acid as before. Of the mineral part of a grain of wheat nearly one-half is phosphoric acid, in rye the proportion is not much less, and in corn it is a trifle more, while in the ash of the other grains and in other vegetable products it is also abundant.

Playing such an important part in both animal and vegetable life, it is well worth the farmer's while to inquire into its properties, and source, and to see to it that it exists in proper quantity and form in the soil on his farm. In the soil it exists in combination with lime, magnesia, iron and alumina, forming neutral phosphates with these elements. Most commonly it is found in combination with lime. These compounds being largely insoluble in water, as the tendency in the soil is always that the phosphate of lime shall be changed to the even more insoluble phosphate of iron, there is practically no loss by drainage, and the only outgo is that occasioned by the removal of crops. Being so scarce in the soil, and at the same time being so essential to plant life, it is not strange that it has been sometimes called "the chemical" of agriculture, and that it is regarded the most important ingredient of the commercial fertilizer.

PHOSPHORIC ACID IN BONES.

The phosphoric acid in fertilizers is derived mostly from bones, guano and phosphate rock. Lately the slag obtained in the 
working of crude iron has come to be recognized in Germany as a valuable source of this ingredient, and thousands of tons of this seemingly worthless product are now yearly ground to powder and utilized for the phosphoric acid they contain. Bones are used as bone meal, bone ash and bone black. Bone meal is obtained by grinding the crude bones to fine powder, and is valuable not only for the phosphoric acid which it contains, but also for its nitrogen. Bones when thoroughly dried consist of about two-thirds earthly matter, and one-third organic or combustible matter. The bones are most easily ground after being steamed, and while this process occasions a loss of nitrogen in the separation of a part of the organic matter, yet the meal is much finer in 'texture, and of greater value in agriculture.

The mechanical condition of bones when applied as a fertilizer is a matter of very great importance. The finer the division the sooner will all of the phosphoric acid become available as food for the plant, and the sooner will the farmer reap the returns from the money expended in the fertilizer. The theory that those manures which make themselves felt over the greatest number of years are the most valuable has long since been questioned, and it is generally conceded that those are to be preferred which will give the maximum return in the shortest possible period. Food prepared for man or animals grows less nourishing and valuable the longer it is unused, and food prepared for the plant should be given in such a condition that it may not remain unconsumed. Food may spoil in the soil, just as food may spoil in the pantry or barn, and a yittle food given often is vastly preferable to an excess given seldom. So thoroughly has this belief been adopted by agriculturists that by patent pulverizing machinery bone flour has been made of such extraordinary fineness that it floated in the air, and while this product would be quick in its action, it was found that it could not be used, as the least wind would blow it from the field.

Bone meal is sometimes classed as fine, medium and coarse, the former being about one-third more valuable than the latter. The meal is often adulterated with gypsum or salt cake, which 
has been added to the bone as a preservative or drier, and sometimes mixed with it coal ashes, ground oyster shells, lime and similar products are found. The demand for bone meal in the arts, and especially in sugar refining, may ultimately take this valuable fertilizer from the market, and the superphosphate of the future will be made more likely from rock phosphate or bone black.

\section{BONE ASH AND BONE BLACK.}

When the bone is subjected to a strong heat, the organic matter referred to is driven off, and the earthy matter, which contains the phosphoric acid, remains as the ash. As the nitrogen in the bone meal is given by the animal matter, or ossein, as it is called, this important fertilizing element is not found in the bone ash. The supply of this substance is obtained chiefly from South America, where stock raising is one of the chief industries of the people, and where bones are used as fuel in the process of extracting the fat from the slaughtered cattle. After the burning this ash is collected and sacked, and being light and compact it is easily handled.

When broken bones are subjected to a strong heat in an iron cylinder without access of air, water, tarry and oily matter and other products are driven off, and a porous residue is left in the cylinder. This residue is of great value for removing coloring matter from liquids, and is largely used by sugar-refiners in purifying brown sugar and other colored substances. After it has served its purpose in this respect, it is still valuable to the agriculturist, as it contains most of the phosphoric acid the fresh bone contained. Being open and porous, this residue is in a finely divided state, but being practically non-nitrogenous, it is less valuable than bone-meal. The different varieties of bone fertilizers may be applied directly to the soil, and excellent results will follow the application, but ordinarily they are treated with sulphuric acid, and the phosphoric acid is then obtained in a more soluble form.

\section{MINERAL PHOSPHATES.}

While the importance of ground bones as a source of phosphoric acid has long been recognized, it is only in recent years 
that the immense trade in mineral phosphates has been built up. The term "South Carolina rock" has become a by-word in scientific agriculture during the past decade, and the bulk of the phosphates in the markets are made from this valuable material. The mineral phosphates are found chiefly as apatites or crystalline phosphates, as phosphorites or amorphous phosphates and as coprolites or fossilized nodules. The apatites are found in veins of volcanic and crystalline rocks both in Europe and America, and are supposed to have been of concretionary origin, having been deposited ont of solution in warm saline springs. The coprolites are traced to animal life, are generally from two to four inches in length, from one to two inches in diameter, from gray to black in color and in the shape of a kidney. They are found in the green sand-stone or cretaceous rocks of England, France, Belgium and Russia. The phosphorites occur largely in Spain, Portugal, Bavaria and elsewhere in Europe, and in this country in South Carolina.

SOUTH CAROLINA ROCK.

The bulk of mineral phosphates used in this country come from South Carolina, in which State, according to Prof. Holmes, the phosphatic deposits underlie no less than 250,000 acres, though the accessible deposits comprise an area not onetenth as great. The phosphatic deposit extends from the headwaters of the Wando river, in a line parellel with the coast and at a distance from it of from ten to forty miles to the headwaters of the Broad river. This is the territory of active operations, but the entire formation is said to extend into North Carolina on the north and Florida on the south, and it has been observed in the interior a distance of sixty miles from the coast. As this rock plays such an important part in the fertilizer trade of the country, the following description of its properties is condensed from Charles U. Shepard's report to the Commissioner of Agriculture of South Carolina:

The most prominent characteristic of the Carolina phosphate is its nodular form. Even where the deposit occurs as an apparently smooth and compact floor, or in large flat cakes, it is, nevertheless, composed of irregular nodules, partially cemented or tightly compacted together. The shape of the nodules is 
egg or kidney form. The exterior is rough and indented, often perforated or even honey-combed by round or irregular holes and cavities, or it is smooth and compact. The surface is occasionally shiny and coated, as it were, with enamel. The masses are wholly devoid of crystalline structure or cleavage, exhibiting occasionally, however, an imperfect lamination. Well preserved casts of eocene shells occur throughout the phosphatic rock, and fossil fish hones and teeth are not infrequently found imbedded in them. The nodules vary in size from a fraction of an inch to several feet in diameter; in weight from almost a ton downwards. The color of the land rock is generally lighter than that found under water or marsh mud, the former having a yellowish or grayish white color, the latter a grayish or bluish black. The masses are easily powdered, and the dust is very fine. The rock gives on friction of its fresh surfaces a peculiar fetid odor, termed by some napthous. This property is the more decided the denser the structure and the higher the content of organic matter. The analyses of the rock vary somewhat, but the average of several hundred show from 25 to 28 per cent. of phosphoric acid, from 35 to 42 of lime, from 4 to 12 of sand and silica, from 2 to 6 of organic matter and combined water, and the remainder consisting of small amounts of sulphuric acid, carbonic acid, magnesia, alumina, sesquioxide of iron, fluorine, sodium and chlorine. The organic matter occasionally yields as high as a quarter per cent. of nitrogen.

Professor F. S. Holmes explains the formation as detached masses of eocene marl, torn off by the action of waves from the great mass of this formation, and swept inland over the sand-bars, which, as also the great marl bed, were covered by the waters of the ocean, to be deposited in those shallow bays and salt water lakes that are now the phosphatic region of South Carolina. Prof. Shepard regards the deeper strata of phosphatic masses as the result of a concentration by carbonic acid of the phosphates sparsely distributed through the overlying marls.

The use of the South Carolina rock in the manufacture of the bulk of commercial fertilizers may be accounted for as follows: It is cheap. It is remarkably free from impurities. It is 
readily ground. It is readily acted upon by sulphuric acid. The superphosphate made from it dries readily, is light, and niay be easily made to contain the amount of soluble phosphoric acid that is required in fertilizers. Its constituents are assimilated by plants more rapidly and effectually than occurs with most other mineral phosphates. Added to these the supply of the rock is extensive, and the source is convenient to the commercial centers.

SLAG FROM CRUDE IRON.

In addition to the bone meal, bone ash, bone black, guano and South Carolina rock already described, a new product has within a year or two made its appearance in the market as a source of phosphoric acid, and bids fair to play an important part in the manufacture of fertilizers in the future. As is well known, pig iron contains a considerable amount of phosphorus, which must be gotten rid of when the iron is converted into steel or forged. The slag obtained in ridding the iron of the phosphorus has been named Thomas slag, and contains the phosphorus originally in the iron. The iron being removed, the slag is broken up, ground and used as a fertilizer. Consul Smith in writing from Mayence, Germany, to the authorities at Washington, states that this product is made up of about 16 per cent. of phosphoric acid, $5^{\circ}$ per cent. of lime, I 2 per cent. of oligist iron and oxidized iron, and 7 per cent. of silicic acid; but the phosphoric acid can run from ro to 25 , per cent. Under the name of patent phosphate meal, a dnst, meal or flour is given to the public made out of manipulated Thomas slag, which contains from 24 to 28 per cent. of phosphoric acid.

It was thought that this substance could not be used as a fertilizer, as it would not dissolve easily enough to make the phosphoric acid available, but experiments have shown that it is only necessary to reduce the slag to a powder to make a fertilizer as effective as bone dust or guano. The German iron works, says Consul Smith, make about 400,000 tons of Thomas slag a year, which can be sold to the farmers, when reduced to a dust, at a price about one-third that of a superphosphate containing an equal amount of phosphoric acid. Professor Wagner, who has experimented largely with this material, claims 
that the form in which the phosphoric acid is contained in Thomas slag is far more decomposable, and much more easily taken up by plants and more easily dissolved by acids and water than the phosphoric acid contained in mineral phosphates. The iron is said to have no prejudicial influence upon plants, and on a wheat soil the slag acts more quickly than the ordinary fertilizer. It is especially recommended for meadow and marsh lands, and in vineyards, orchards and gardens it provides a good soil for the plants to strike itheir roots into for life and moisture.

THE NATURF OF A SUPERPHOSPHATE.

Following the description of those substances which furnish phosphoric acid to the fertilizer, the use of sulphuric acid in agriculture may be explained. This acid is commonly known as the oil of vitriol, and is a thick oily liquid with a specific gravity nearly twice as great as that of water. It is the most useful acid known, as by its means many of the other acids are prepared, and so important is it in the arts and manufactures that it has been said that the commercial prosperity of a country may be indicated by the amount of sulphuric acid it consumes. When bone meal, bone ash, bone black or phosphatic rock is applied to the soil, the phosphoric acid which they contain is largely insoluble in water, and the maximum results from their application may not for some time be obtained. Especially is this true of the phosphatic rock, the insoluble phosphoric acid having a less value than that contained in bone, and from the application of this rock in the raw state very meager results would be obtained. It was Baron Liebig who first suggested that if the bones or mineral phosphates be treated with sul. phuric acid, a chemical change would take place by which the insoluble phosphoric acid would be changed to the soluble form, and a considerable amount of gypsum would also be obtained.

This change may be more readily understood when it is stated that the tri-calcic-phosphate of lime as found in the raw bone or rock, is made up of one equivalent of phosphoric acid and ihree equivalents of lime. When sulphuric acid is added to the rock or bone, two equivalents of lime enter into combination with the acid, and the remaining compound 
has now only one equivalent of lime to one equivalent of phosphoric acid, with some water added which is given up by the acid. Thus a substance is obtained which is richer in phosphoric acid than before the treatment with sulphuric acid, and what is far more to the point this new substance is in a much more finely divided state, and the phosphoric acid is now almost completely soluble in water. These points being gained, the substance may now be applied as a fertilizer, and from their application far better results than from the raw bone or rock will be obtained.

The difference in the size of the particles of the finest bone dust before being treated with the acid and afterwards has been cirefully ascertained. According to the measurements of Prof. O. N. Rood, of Troy, by the use of the microscope, the smallest particles of bone dust would not average less than I-IOO of an inch in diameter, while the same particles after being so treated with the acid, and so changed to the superphosphate, would measure only I-23,000 of an inch in dianseter. What is comnıonly known as dissolved bone to the fertilizer trade is bone treated with sulphuric acid, and an acid phosphate is generally rock treated in the same nanner. Common usage has restricted the term acid phosphate to the fertilizers containing only phosphoric acid, while the superphosphate is the same with the addition of substances containing potash and nitrogen. In some States, however, the term acid phosphate is applied to fertilizers which contain less than ro per cent. of arailable phosphoric acid and less than 2 per cent. of ammonia, while ammoniated superphosphates contain more than $S$ per cent. of available phosphoric acid and more than 2 per cent. of ammonia. The names of the various brands are subject to the whims of the manufacturers.

TIE SOURCES OF POTASH.

In former years wood ashes were the only available source of potash. They contained on the average about 4 pounds of the potashes to $4^{S}$ pounds or a bushel of the ashes, and when transportation to a distance was not necessary they served their purpose well. When the forests began to be exhausterl, and coal came generally into use, the supply of ashes was largely de- 
creased, and the discovery of some other potash fertilizer" was anxiously awaited. This discovery was made about thirty years ago in Germany, when a large deposit of potash salts was opened up near Stassfurt, and now these salts are so cheap that they may be utilized to advantage on every farm. The lower stratum of this vast deposit consists of a bed of salt of unknown depth. Above this salt is another bed of salt and potash minerals, with which is mixed some soda, magnesia and lime, the whole being about 250 feet in thickness. The supply seems to be almost inexhaustible, and the cost of extracting the mineral is so little that the cost of potash as reckoned in the average fertilizer is scarcely more than one-half as great as that of the soluble phosphoric acid, and not one-third as great as that of the nitrogen.

Most of the potash in the soil comes from the decomposition of feldspar, and some from mica and other minerals. When the feldspar is decomposed a clay soil is formed, and as this decomposition goes on slowly a supply of potash is beung continually furnished. E. M. Pendleton, of Georgia, gives a table of the analyses of IOI American and 25 English soils, and the average amount of potash in each is a trifle more than seven-tenths of one per cent. The strong clay soil will contain a very much higher percentage, and the light sandy soil a very much lower. The clay soil is strong, because it has enduring fertility, and it has the fertility largely in consequence of having the potash.

The potash is in the soil in the form of double silicates, and hence not easily washed out. The orily loss is from the removal of crops. Nor does it accumulate in fruits and seeds as phosphoric acid, but being in the hay, fodder and stalks it largely remains on the farm. When sugar beets, tobacco, carrrots, turnıs, onions, clover, hops, beans, peas or potatues are raised in quantity, and sent to the market, a great deal of potash is sold in these products. and if the soil be sandy the loss must be made good. An average crop of wheat will remove about 25 pounds of potash to the acre, an average crop of potatoes four times as much, and an average crop of tobacco twice as much as the potatoes. In addition to the wood ashes, and the American potashes which are made from the ashes and the sulphrates and chlorides which come trom Germany. as a 
source of potash green sand marl is used in New Jersey, and the ashes of cotton seed hulls in some parts of the south. On the average farm the supply of potash is not likely to be so soon exhausted as that of phosphoric acid or nitrogen.

MODES OF APPLYING ARTIFICIAL FERTILIZERS.

The following directions for the application of fertilizers, and the crops best suited for each are condenced from Storer's recent work on Agriculture. What needs to be done in order to secure their proper diffusion and distribution in the soil can now be said. For example, superphosphate, nitrate of sodium and even sulphate of ammonium may be merely scattered on the surface of the land, since they will soak into the soil readily enough. Bone meal, oil cake and fish scrap, need only be buried deeply enough, in not too dry earth, that they may nitrify readily. Bone ash, bone black and phosphatic guano need to be buried pretty deeply, and well commingled with the soil. With them, as with potash salts, it would be well, were it not for the trouble involved, to apply one portion of the dressing before ploughing the land, another before crossploughing it, and another before harrowing, to insure thorough distribution.

In Germany potash salts are particularly commended for beets, potatoes, clover, cabbages and hops-all leafy plants it will be noticed. But it is upon clover especially and other leguminous plants that potassic manures show the most remarkable effects. Meisrs. Lawe̊s and Gilbert in experiments with a variety of different plants, continued through long terms of years, found the potassic manures more useful with clover, beans and peas than with any other crops. Dr. Gilbert has recently summed up his experience in the following terms: It is found, he says, that easily assimilable nitrogenous manures have generally a very striking effect in increasing the growth of grain crops, such as wheat, barley and oats; although these grain crops contain comparatively little nitrogen, and take but little of it from the land. The leguminous crops, on the other hand, such as peas, beans, clover and others, although highly nitrogenized, are by no means characteristically benefited by the use of direct nitrogenous manures, such as ammonium salth 
and nitrates, though nitrates act much more favorably than ammonid salts. It appears, indeed, that we may say, "Use phosphates for turnips and such like roots, potash for leguminous plants and active nitrogen for grain.

THE FERTILIZER ANALYSIS EXPLAINED.

In West Virginia the law requires that the analysis of the fertilizer shall be printed on every sack. It has frequently been stated, and with a great deal of truth, that the farmer does not understand the terms that are used, and is, therefore, not in a position to select that fertilizer which his particular crop or soil may need. The nature of the various ingredients of which the fertilizers are composed have already been fully described, and it only remains to explain the terms which are found on every sack. The moisture is generally the first determination given, and this mostly varies between 9 and $\mathrm{I}_{5}$ per cent. A fertilizer which contains 12 per cent. of moisture contains $x 2$ pounds of water in ever roo pounds of the fertilizer or 240 pounds of water in every ton. This moisture should be taken into account in estimating the value of the product, as every pound of water adds so much to the cost of transportation. This moisture is subject to variations with the climate and condition of the atmosphere, and in the case of a second analysis a considerable discrepancy may be noticel. The chemist in making an analysis of an acid phosphate will use scarcely more than a spoonful of the mixture, and as this amonnt is accurately weighed, a variation in the moisture will produce a variation in the phosphoric acid. The variation in two analyses may be slight, but when the amount is computed in a hundred tons of the fertilizer the variation becomes important.

The soluble phosphoric acid means the phosphoric acid that is soluble in pure cold water, and this is the most valuable form of the acid that is found in the fertilizer. This is made soluble, as before explained, by treating the bones or mineral phosphates with sulphuric acid, and when applied to the soil it becomes immediately available for plant-life. Being thoroughly distributed throughout the soil, it may become insoluble after it has soaked into the earth, but before this has happened the mechanical distribution has been completed. 
The reverted phosphoric acid means that which is insoluble in pure cold water, but is soluble in a neutral solution of citrate of ammonium under the standard conditions. This form of the acid was originally soluble in pure cold water, but from the reaction of the iron and alumina it has partly gone back or reverted. Another explanation of its presence is given in the statement that when not enough sulphuric acid has been used in the manufacture, it is claimed that the insoluble phosphate which has not been decompused reacts upon the soluble and changes a part of it to the reverted form. In most of the States the reverted phosphoric acid has nearly the same commercial value as the soluble, for when applied to the soil, like the soluble, it soon becomes available for plant-life.

The insoluble phosphoric acid means that which is neither soluble in pure cold water, nor in the solution of citrate of ammonium, but is soluble in the stronger acids. This is the form in which it exists in nature in the bone or phosphatic rock, and its commercial value is largely determined by the source from which it is derived. In general, the bone products dissolve more readily than the rocks, though appreciable quantities of the latter will in time dissolve in the soil by the action of the humic acid, carbonic acid, saline solutions and plant-ronts. The phosphoric acid in dry fine ground fish and in fine bone and tankage is almost as valuable as that soluble in water; and in meclium and coarse bone the value is still less. In fine ground mineral phosphate the value is abont one-fourth that of the acid soluble in water, but in many States the insoluble acid of the superphosphate is given no value whatever.

The available phosphoric acid is the sum of the soluble and reverted, and the total is the sum of the insoluble and available. If the fertilizer be an acid phosphate, only the above determinations will be found on the sack, except in some States as before stated; if it be an acid phosphate with potash, then the potash percentage will also be found, and if it be one of the many varieties of ammoniated superphosphates, then to the phosphoric acid determinations will be added thuse of potash and nitrogen. The potash is generally reckoned as the oxide of potassium, and if obtained from the high grade sulphate it is commercially 
worth about one cent more per pound than if obtained from kainite or the muriate. The commercial value of the potash from these latter sources is a trifle more than one-half as much as that of the phosphoric acid soluble in water and about onefourth as much as nitrogen in its best forms. The nitrogen is sometimes reckoned as such and sometimes as ammonia. If reckoned as ammonia the actual nitrogen may be obtained by dividing the percentage by $I 7$ and then multiplying the result by $\mathrm{I}_{4}$. This is by far the most expensive element in the fertilizer.

FERTILIZER CALCULATIONS.

The terms found on every sack having now been explained, the farmer may easily determine how many pounds of each ingredient will be obtained in every ton of the fertilizer. If the analysis, for example, shows ro per cent. of available phosporic acid, 2 per cent. of insoluble, 3 per cent. of potash and 2 per cent. of nitrogen, then in every one hundred pounds of the fertilizer are ro pounds of the available acid, 2 of the insoluble, 3 of potash and 2 of nitrogen, and in every ton are 200 pounds of the first ingredient, 40 of the second, 60 of the third and 40 of the fourth. If the farmer wishes to go a step further, and in addition to finding the number of pounds of each ingredient to the ton, he wishes to estimate the commercial value of each ton of the fertilizer, he may do so with little trouble and expense, and, therefore, be able to tell whether he is asked a just price for the fertilizer which is offered to him for sale. Before attempting this calculation he must first ascertain the trade values of the various ingredients contained in the fertilizer, and he must also judge approximately of the source of these in the mixture. At the beginning of every fertilizer year these trade values are made up by several of the Experiment Stations of the East, and are the prices at which the raw materials and chemicals can be purchased in the eastern markets. To these may be added from three to four dollars per ton, which the manufacturers claim is the cost of mixing, handling and cartage, and also the cost of transportation. These trade values for the years $I S S 7$ and $I S S S$ are given in the following table, and they will be ascertained hereafter every year by the West Virginia Experiment Station. 
Trade Values of Fertilizing Ingredients in Raw Materials AND Chemicals For is 88 .

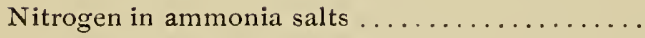

in nitrates

$$
1887 \text {. }
$$

I888.

cts. per lb. cts. per lb.

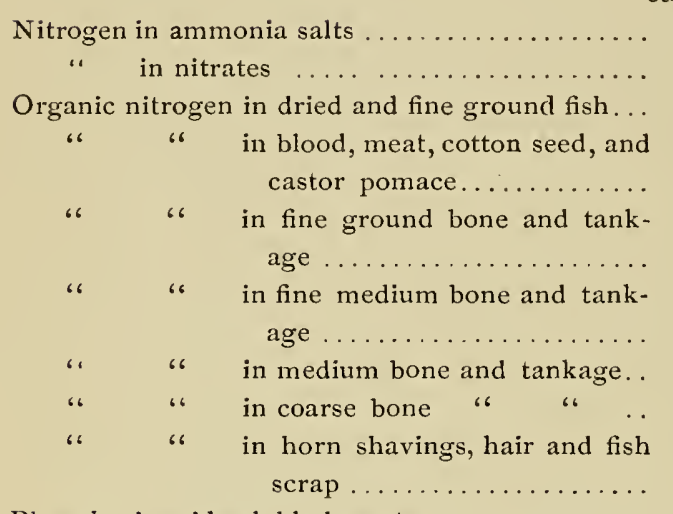

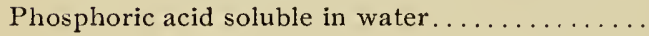

$\begin{array}{ll}171 / 2 & \text { I7 } 1 / 2 \\ 16 & \text { I6 }\end{array}$

$171 / 2 \quad 161 / 2$

$17 \frac{1}{2} \quad 161 / 2$

16

$161 / 2$

$\begin{array}{ll}14 & 13 \\ 18 & 101 / 2 \\ 10 & 81 / 2\end{array}$

" " " 6 in ammonium citrate...

" " in dry fine ground fish and in fine

bone and tankage..........

" " in fine medium bone and tankage.

" " in medium bone and tankage...

" " 6 in coarse bone and tankage ....

" " in fine ground rock phosphate...

Potash as high grade su'phate ............

$\therefore$ " "kainite ...................

". " muriate

$\begin{array}{ll}8 & 8 \\ 8 & 8 \\ 71 / 2 & 7 \frac{1}{2} \\ 7 & 7 \\ 6 & 6 \\ 5 & 5 \\ 4 & 4 \\ 2 & 2 \\ 5 \frac{1}{2} & 5 \frac{1}{2} \\ 4 \frac{1}{4} & 4 \frac{1}{4} \\ 41 / 4 & 4 \frac{1}{4}\end{array}$

If now the nitrogen is in the best form in the fertilizer it may be rated in general at $r$ cents a pound, the available phosphoric acid at 8 , the insoluble at 3 , and the potash at $4 \frac{1}{2}$. This will probably be near enough the truth to enable the farmer to get at the approximate value of the fertilizer. If, now, in the example above given, the fertilizer contain $200 \mathrm{lbs}$. of available phosphoric acid, 40 of the insoluble, 60 of the potash and 40 of the nitrogen to the ton, then the value of the first ingredient is $\$ 16$, of the second $\$ 1.20$, of the third $\$ 2.70$ and of the fourth $\$ 6.80$, making the fertilizer worth $\$ 26.70$ per ton. Supposing the fertilizer to be as represented, and this is generally the case with all of the standard brands, and taking some minor consid- 
erations into account, as agents' fees, losses from bad debts, the question of cash or credit, the tarmer is now in a position to judge whether a fair price is asked for the product which is offered to him for sale.

COMMERCIAL VALUE NOT NECESSARILY THE AGRICULTURAL.

In this connection the farmer must not suppose that the commercial value of the fertilizer necessarily represents the agricultural value on his particular soil or farm. The two values may have very diff rent meanings on different farms, and the latter can only be determined by taking into account the character of the soil and the kind of crop that is to be raised. If a soil be simply deficient in phosphoric acid but with sufficient nitrogen and potash for present needs, then an acid phosphate costing $\$ 20$ per ton may give as good results for the present as a high priced ammoniated superphosphate costing double that sum. In the one case that ingredient is purchased, which the soil immediately needs, while in the other potash and costly nitrogen are also purchased for which the soil stands in no immediate need. In eastern Pennsylvania where there is a deficiency of phosphoric acid in the soil, acid phosphates are used year after year to good advantage, while in the Connecticut valley and in the worn-out tobacco regions of the South potash is the element to be especially looked after in the fertilizer.

In using a special fertilizer, however, great care must be exercised. It must never be forgotten that such a manure is supplying one essential ingredient in abundance to the soil, while the crop is removing the two others as well. "Special fertilizers," says a prominent writer, "require great care in their use, and as sometimes used it would often be more just for the tenant to give the landlord compensation for having deteriorated his land." During a few years in Maryland the yield of wheat was very largely increased by the use of guano, but it was found that this increase was not a lasting one, and after a time this highly nitrogenized fertilizer seemed powerless. The same has been noted of acid phosphates and potash salts in other sections, and the explanation iies in the fact that while 
one essential ingredient is added the other two are left entirely out of the calculation. An acid phosphate should not be purchased simply because it is cheap, but because the farmer is satisfied that his soil needs only phosphoric acid. In this connection a quotation from Scott and Morton's "Soil of the Farm" will be of general interest.

A general fertilizer, say these writers, contains all the constituents of the crop, or at least all those in which soils are most deficient; but it by no means follows that every substance which may act beneficially ought to be applied. If a soil is deficient in one particular element, and contains all the other requisites of fertility, that one substance may act as beneficially when applied as though it contained all the constituents of the crop. The crop in this case is thrown upon the natural resources of the soil for all its other elements. By persisting in the use of a special fertilizer, an ultimate exhaustion of the soil is in $\epsilon$ vitable. Judiciously used special fertilizers are the agents which bring into useful activity the dormant resources of the soil; they restore the proper balance between its principal constituents, and supply the excessive demand for some particular elements. Still the application useful on one soil may be quite useless on another.

In summing up the results of the foregoing observations it is evident that the farmer who wishes to use commercial fertilizers intelligently, must not only make himself familiar with the character of their ingredients, but also with the nature of the soils upon which they are to be used, and the crops which are to be grown. He must remember in addition that the resources of nature may be readily exhausted, and that when the soil has become barren from injudicious cropping, the ingredients that are wanting must be returned in their proper form and proportion. The advance in scientific study in recent years has been marvelous, indeed, and nowhere has this advance been more strikingly felt than on the farm. New and improved machines have been introduced, artificial foods have been prepared, and improved stock and crops have been raised. In the use of commercial fertilizers has this knowledge been 
especially valuable, and the different operations in connection with agriculture are now carried out on scientific principles. When these principles are more widely disseminated, and the nature of the different soils and crops are better understood, then will the food supply for plants and animals be more readily obtained, and the methods of scientific agriculture will everywhere be adopted. 
